\title{
Avaliação do potencial citotóxico e genotóxico de Plantago major L. em sistemas teste in vivo
}

\author{
LUZ, A.C.; PRETTI, I.R.; DUTRA, J.C.V.; BATITUCCI, M.C.P.* \\ Universidade Federal do Espírito Santo(UFES), Departamento de Ciências Biológicas, Avenida Marechal Campos, \\ 1468, CEP: 29040-090, Vitória-Brasil *docarmo_batitucci@yahoo.com.br
}

\begin{abstract}
RESUMO: A infusão das folhas de Plantago major (Plantaginaceae), conhecida como tansagem ou transagem, é usada como antibiótica, antiinflamatória, anti-séptica, anti-térmica, na prevenção de tumores e no tratamento de neoplasias. Este efeito é atribuído aos flavonóides encontrados em diversas espécies do gênero Plantago. O presente estudo objetivou avaliar os potenciais efeitos, tóxico e mutagênico, do extrato bruto hidroalcoólico de folhas de $P$. major, por meio dos testes in vivo de Allium cepa e do micronúcleo. Para o ensaio biológico vegetal, meristemas de raízes de $A$. cepa foram usados para o preparo de lâminas através da técnica de esmagamento. No ensaio do micronúcleo foram analisadas lâminas de células de medula óssea de roedores. As análises estatísticas seguiram o teste de Tukey $(p \leq 0,05)$ para o ensaio de Allium cepa e teste de Scott-Knott $(p \leq 0,05)$ para o ensaio do micronúcleo. Os resultados do teste de Allium cepa demonstram que houve redução significativa no índice de germinação em todas as concentrações testadas. $P$. major provoca alteração no ciclo celular pela inibição da divisão das células, como indica o índice mitótico. Os índices de efeitos clastogênico e aneugênico demonstram que, além de não determinar aumento de aberrações cromossômicas, o que indica ausência de ação genotóxica, P. major possui atividade anti-genotóxica. Os resultados do teste do micronúcleo reforçam a sugestão de que o extrato de P.major não possui atividade mutagênica, entretanto provoca alterações na divisão celular.
\end{abstract}

Palavras-chave: mutagênese, tansagem, plantas medicinais, Allium cepa, micronúcleo

ABSTRACT: Evaluation of the cytotoxic and genotoxic potential of Plantago major L. in test systems in vivo. The infusion of leaves of Plantago major (Plantaginaceae), known as "tansagem" or "transagem", is used as antibiotic, anti-inflammatory, anti-septic, anti-thermal in the prevention of tumors and in the treatment of neoplasms. This effect is attributed to the flavonoids found in diverse species of the genus Plantago. The present study aimed to evaluate the potential toxic and mutagenic effects of the crude hydroalcoholic extract from $P$. major leaves by means of in vivo tests with Allium cepa and micronucleus. For the plant biological assay, meristems of $A$. cepa roots were used for the preparation of slides by adopting the crushing technique. In the micronucleus assay, slides of bone marrow cells from rodents were analyzed. Statistical analyses were carried out according to Tukey's test $(\rho \leq 0.05)$ for the Allium cepa assay and Scott-Knott test $(\rho \leq 0.05)$ for the micronucleus assay. Results of the $A$. cepa test demonstrate that there was a significant reduction in the germination index at all tested concentrations. P. major causes alteration in the cell cycle by inhibiting the division of cells, as indicated by the mitotic index. The indexes of clastogenic and aneugenic effects show that, in addition to not determining the increase in chromosomal aberrations, which indicates the absence of genotoxic action, P. major has anti-genotoxic activity. Results of the micronucleus test reinforce the suggestion that $P$. major extract does not have mutagenic activity but causes alterations in the cell division.

Key words: mutagenesis, tansagem, medicinal plants, Allium cepa, micronucleus

Recebido para publicação em 07/12/2011

Aceito para publicação em 22/05/2012

Rev. Bras. PI. Med., Botucatu, v.14, n.4, p.635-642, 2012. 


\section{INTRODUÇÃO}

Há milhares de anos o homem utiliza os recursos vegetais com fins terapêuticos. As propriedades curativas das plantas se tornaram parte da cultura popular através da observação e experimentação pelos povos (Ko, 1999). As plantas medicinais são importantes por fornecerem fármacos de difícil síntese química, por seus produtos serem protótipos para produção de fármacos e por possibilitarem a modificação dos compostos tornando-os mais eficazes ou menos tóxicos (Robbers et al., 1996; Tyler, 1996).

Dentre as plantas com potencial medicinal, está a Plantago major (Plantaginaceae), popularmente conhecida como tansagem. Esta espécie compõe a Relação Nacional de Plantas Medicinais de Interesse ao Sistema Único de Saúde - RENISUS. A infusão das folhas de Plantago majoré usada como antibiótica, antiinflamatória, anti-séptica, anti-térmica, na prevenção de tumores e no tratamento de neoplasias (Samuelsen, 2000). Os efeitos, preventivo e inibidor, no desenvolvimento de cânceres são atribuídos aos flavonóides encontrados em diversas espécies do gênero Plantago (Galvéz et al., 2003). Além dos flavonóides outros componentes químicos encontrados nesse vegetal são mucilagens, taninos, alcalóides (plantagonina, indicaína), iridoide glicosilado (aucubina), alantoína, ácidos clorogênico e ursólico, esteróides e saponinas (Lorenzi \& Matos, 2002).

Compostos dos extratos vegetais podem causar doenças e até a morte por ação de agentes naturais mutagênicos e carcinogênicos, justificando o interesse em determinar os riscos no uso medicinal desses extratos (Chacon et al., 2002). Mutações gênicas atuam em etapas do processo de carcinogênese humana, e testes que detectem compostos genotóxicos permitem identificar substâncias que ofereçam risco à saúde humana (Ribeiro et al., 2003). Portanto, a avaliação dos efeitos mutagênicos, além de referendar o emprego de plantas medicinais, acrescenta segurança ao usuário de fitoterápicos, pois estará contando com um medicamento validado cientificamente.

Dentre os testes de avaliação toxicológica recomendados pelas agências internacionais e instituições governamentais, o ensaio de micronúcleo em medula óssea de roedores é amplamente utilizado para avaliação e registro de novos produtos químicos e farmacêuticos que entram no mercado mundial, como um estudo toxicológico preliminar (Ribeiro et al., 2003; Tagliati et al., 2008), visto que os resultados obtidos são considerados fortemente relevantes no contexto humano (Morita et al., 1997). Outro teste que se destaca é o teste de analise de raízes de Allium cepa, uma vez que as raízes ficam em contato direto com a substância testada (Macedo et al.,
2008). Autilização de ensaios biológicos vegetais para o monitoramento da bioatividade de extratos, frações e compostos isolados de plantas têm sido frequentemente incorporados à identificação e monitoramento de substâncias potencialmente tóxicas (Noldin et al., 2003). Testes de citotoxicidade a partir de sistemas vegetais são validados por pesquisadores que o realizam conjuntamente ao teste animal in vivo, como o teste de micronúcleo, e os resultados obtidos são similares (Vicentini et al., 2001; Teixeira et al., 2003). Esse estudo objetivou caracterizar a espécie Plantago major quanto às propriedades mutagênicas, indicando se é segura ou não - nos aspectos aneugênicos, clastogênicos e tóxicos - para uso terapêutico.

\section{MATERIAL E MÉTODO}

Aquisição e Preparo do Material Vegetal

Os espécimes de Plantago major foram adquiridos em estabelecimento comercial do município de Vitória-ES. O material vegetal fresco foi submetido à secagem em estufa, com circulação de ar, à temperatura de $40^{\circ} \mathrm{C}$ por sete dias. Excicatas do material botânico foram depositadas no Herbário VIES da Universidade Federal do Espírito Santo, onde os espécimes foram identificados, e registradas sob o número 14.771.

\section{Obtenção do Extrato}

Para o preparo do extrato hidroalcoólico utilizou-se $700 \mathrm{~mL}$ de etanol $80 \%$ para cada $60 \mathrm{~g}$ de material vegetal seco e picado. Após maceração por 72 horas, protegida da luz e à temperatura ambiente, a solução foi filtrada em papel, com auxílio de bomba a vácuo. A mistura líquida obtida foi evaporada $a 0^{\circ} \mathrm{C}$. Para definir a concentração do extrato preparado foi determinada a massa seca do mesmo, que teve o valor de $0,45 \mathrm{mg}$ de extrato bruto para cada $100 \mathrm{mg}$ de extrato pastoso.

\section{Animais}

Os animais utilizados neste estudo foram obtidos no biotério do Programa de Pós-graduação em Ciências Fisiológicas da UFES e mantidos com alimentação ad libitum com temperatura e ciclo noitedia controlados.

\section{Testes para análise de mutagenicidade Teste de Allium cepa}

Para a avaliação dos efeitos citotóxicos e genotóxicos, submeteu-se sementes de Allium cepa aos tratamentos, contínuo e descontínuo, com extrato bruto hidroalcóolico de folhas de P. major (EBHPM). O extrato obtido após a evaporação do álcool usado 
na obtenção foi diluído em água destilada para se obter as concentrações de 0,5; 1,0 e 2,0 mg mL-1. No tratamento contínuo as sementes germinaram diretamente no EBHPM até atingirem cerca de $2 \mathrm{~cm}$ de comprimento, quando foram coletadas. No tratamento descontínuo as sementes germinaram em água destilada até atingirem $2 \mathrm{~cm}$, sendo posteriormente transferidas para o EBHPM, a coleta das raízes foi realizada após 20 horas (tratamento agudo) e 72 horas (tratamento crônico). Em ambos os tratamentos as concentrações testadas foram 0,5 ; 1,0 e $2,0 \mathrm{mg} \mathrm{mL}^{-1}$. Para controle negativo (CN) as sementes germinaram em água destilada. As sementes foram fixadas em Carnoy e as lâminas confeccionadas segundo Fiskesjö (1985), coradas com Reativo de Schiff e carmin acético 1\%. Foram analisadas 5000 células por tratamento. Foram avaliados os índices mitótico de efeito clastogênico (micronúcleo, quebras e pontes cromossômicas) e de efeito aneugênico (C-metáfases, anáfases multipolares, perdas, aderências e atrasos de cromossomos e células binucleadas) em ambos os tratamentos, além do índice de germinação avaliado no tratamento contínuo. Para avaliação do índice de germinação, utilizaram-se quatro repetições de 50 sementes cada, colocadas em placas de Petri cobertas com papel toalha, sendo as sementes mantidas sob temperaturas constantes de $25^{\circ} \mathrm{C}$ e $30^{\circ} \mathrm{C}$, por cinco dias.

\section{roedores}

Teste do micronúcleo em medula óssea de

Para a realização da análise de micronúcleos, segundo MacGregor (1987), utilizaramse camundongos adultos jovens e saudáveis, com idade entre 7 a 12 semanas, separados em diferentes grupos experimentais, identificados de acordo com as concentrações a serem testadas e os controles negativo e positivo, sendo constituídos de 6 animais cada ( 3 machos e 3 fêmeas). Os animais utilizados nestes experimentos foram obtidos no biotério da Universidade Federal do Espírito Santo, mantidos com alimentação e dessedentação ad libitum. O EBHPM foi administrado, por cinco dias, em doses de $100 \mathrm{e}$ $200 \mathrm{mg}$ por animal, de acordo com o grupo experimental, via gavage. Utilizou-se um grupo como controle negativo $(\mathrm{CN})$, o qual recebeu o veículo (água destilada), e um grupo como controle positivo (CP), que foi tratado com ciclofosfamida (50 $\mathrm{mg} \mathrm{kg}^{-1}$ ) intraperitonialmente. Foram analisados a porcentagem de Eritrócitos Policromáticos Micronucleados (EPCMN) e a relação entre o número de eritrócitos policromáticos (EPC) e o número total de eritrócitos, que corresponde a soma dos eritrócitos policromáticos (EPC) e os normocromáticos (ENC): $\mathrm{EPC} /(\mathrm{EPC}+\mathrm{ENC})$.

\section{Análise estatística}

A análise estatística empregada foi o teste de Tukey, para o ensaio de Allium cepa e o teste de Scott-Knott, para o ensaio do micronúcleo em medula óssea de roedores. Diferenças estatísticas foram fixadas como sendo significativas para $\rho \geq 0,05$.

\section{RESULTADO E DISCUSSÃO}

Os índices de germinação (IG) das sementes de Allium cepa, sob tratamento contínuo no EBHPM, foram de 58, 32 e $6 \%$ para as concentrações 0,$5 ; 1,0$ e 2,0 mg mL-1, respectivamente. Para o CN este índice foi de $84 \%$, como mostrado na Figura 1. Esses resultados indicam que houve redução significativa

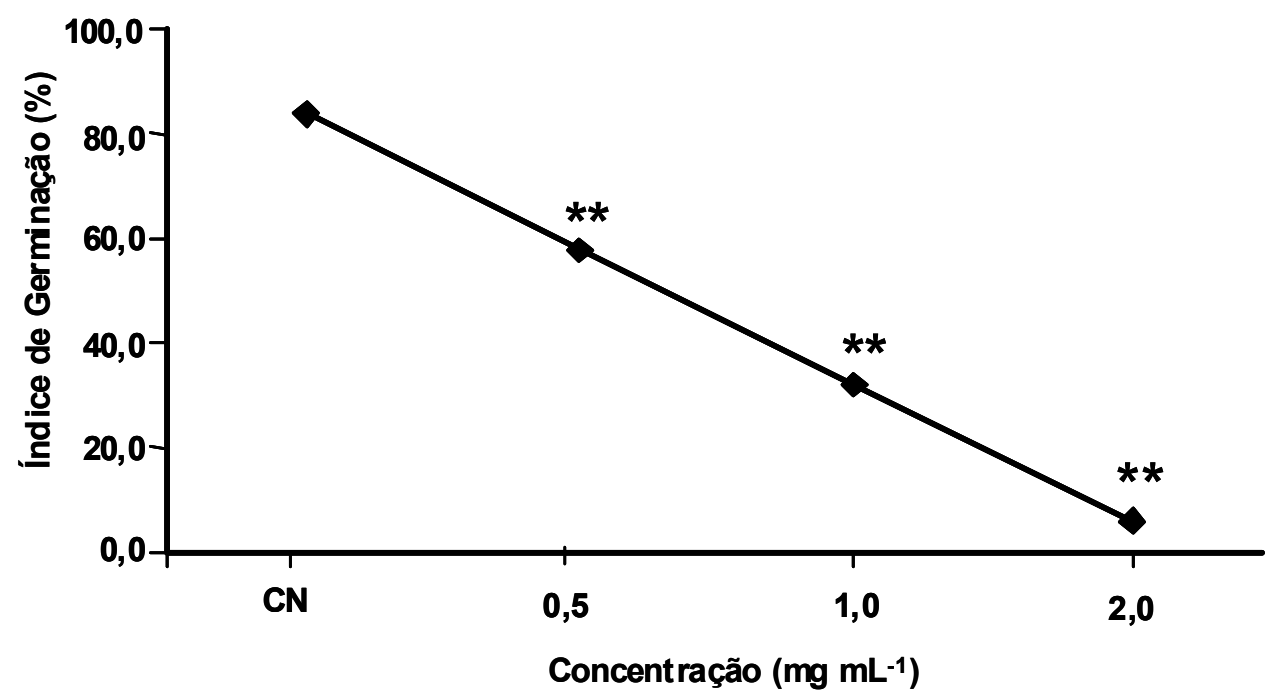

FIGURA 1. Índice de germinação das sementes de $A$. cepa em resposta ao tratamento contínuo com o extrato hidroalcoólico de folhas de Plantago major, nas concentrações de 0,5; 1 e $2 \mathrm{mg} \mathrm{mL}^{-1}$ e o controle negativo (CN). Nível de significância $\left.p \geq 0,01{ }^{* *}\right)$. 
no IG em todas as concentrações testadas, sendo o índice afetado proporcionalmente ao aumento da concentração do extrato.

O teste de germinação com vegetais é um modelo amplamente utilizado para avaliar o potencial aleloquímico de extrato da planta ou de substâncias isoladas, e um dos efeitos previstos quando determinado composto interfere no funcionamento celular é a alteração no índice de germinação das sementes, revelando ação tóxica e/ou citotóxica. Um agente pode ser considerado tóxico quando promove redução superior a $50 \%$ no índice de germinação de sementes de Allium cepa, em relação ao controle negativo (Fiskesjö, 1985). Nesse estudo, sementes tratadas com concentração igual ou superior a de $1,0 \mathrm{mg} \mathrm{mL}^{-1}$ do EBHPM mostraram redução na porcentagem de germinação maior que $50 \%$, o que aponta citotoxicidade do extrato acima dessa concentração. Segundo Rodrigues et al. (1992), os compostos alelopáticos são inibidores de germinação e crescimento, pois interferem na divisão celular, permeabilidade de membranas e na ativação de enzimas. Assim, redução na germinação das sementes frente ao aumento das concentrações utilizadas indica um efeito tóxico, que pode ser decorrente de ação alelopática de influência negativa do extrato sobre as sementes de Allium cepa (Figura 1). Esses dados demonstram que as concentrações testadas estão próximas do limite para toxicidade de $P$. major em células vegetais. Essa é uma informação importante para a regularização do uso terapêutico, visto que se preparada como chá ou infusão, as doses dificilmente atingirão as concentrações testadas no presente trabalho, mas na forma de cápsulas ou comprimidos as doses atingidas podem ser iguais ou até maiores que essas, o que poderá acarretar danos ao material genético dos indivíduos submetidos ao tratamento.
Os índices mitóticos (IM) do tratamento contínuo (TC) foram 0,$062 ; 0,051$ e 0,023 para as concentrações 0,$5 ; 1,0$ e 2,0 mg mL-1, respectivamente. Para o $\mathrm{CN}$ este índice foi de 0,076 . Neste tratamento, apenas a concentração de $2,0 \mathrm{mg}$ $\mathrm{mL}^{-1}$ apresentou diminuição significativa do IM em relação ao CN. No tratamento descontínuo (TD) 20 horas, estes índices foram 0,033; 0,024 e 0,017, sendo o IM do CN igual a 0,076. Todas as concentrações testadas neste tratamento apresentaram-se diferentes estatisticamente ao $\mathrm{CN}$, com a redução do IM. Quanto ao TD 72 horas, os IM foram 0,037; 0,016 e 0,024 , tendo o $C N$ índice mitótico de 0,076 . Portanto, a redução no IM é relevante em concentrações iguais ou maiores que $1,0 \mathrm{mg} \mathrm{mL}^{-1}$ (Figura 2 ), sugerindo que o extrato interfere no ciclo celular normal por inibição da divisão das células, o que demonstra que este extrato possui atividade citotóxica, visto que a citotoxicidade de uma substância pode ser determinada pelo aumento ou diminuição do IM das células submetidas a sua exposição (Carvalho et al., 2005).

A atividade enzimática associada aos flavonóides pode ser responsável pela inibição da divisão celular (Teixeira et al., 2003). Os extratos aquosos de Baccharis trimera e B. articulata apresentaram inibição da divisão celular na concentração de $15 \mathrm{mg} \mathrm{mL}^{-1}$ do extrato, em ensaio de Allium cepa, bem como alterações celulares indicando a ocorrência de atividade antiproliferativa e mutagênica, sendo essa inibição atribuída aos flavonóides identificados pela prospecção fitoquímica (Fachinetto et al., 2009). Os flavonóides de Humulus lupulus L. e Lonchocarpus spp. apresentaram atividade citotóxica e antiproliferativa sob o ciclo celular de células cancerosas de próstata (Delmulle et al., 2006; Borges-Argáez et al., 2007). Outras espécies medicinais, que possuem taninos e

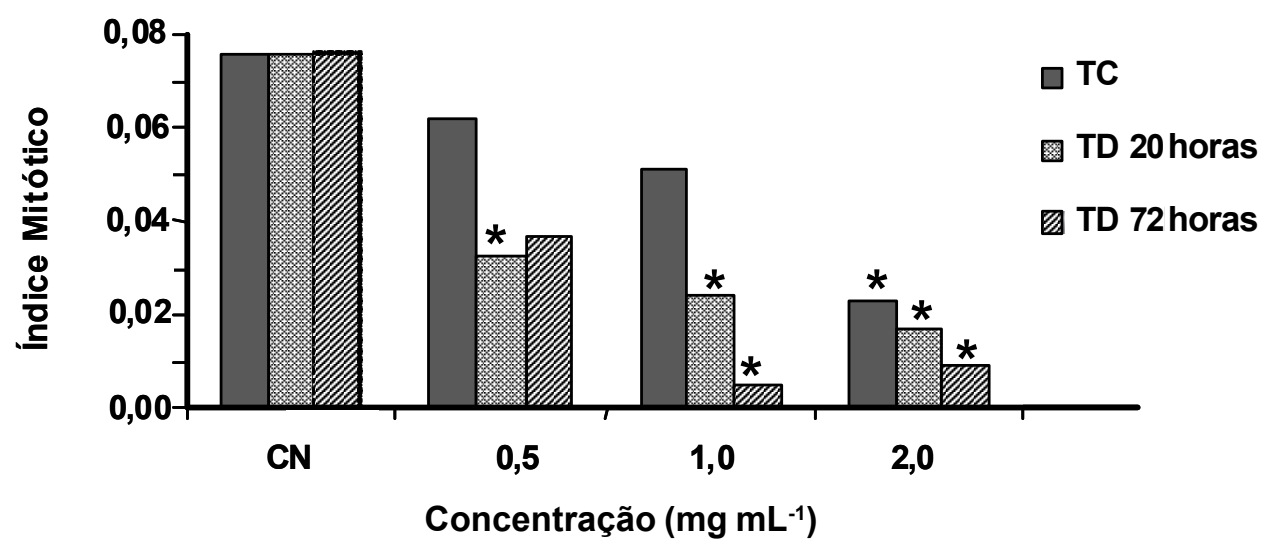

FIGURA 2. Índice Mitótico de células meristemáticas de Allium cepa expostas aos tratamentos contínuo, descontínuo 20 horas e descontínuo 72 horas, com o extrato hidroalcoólico bruto de folhas de Plantago major, as concentrações de 0,$5 ; 1,0$ e $0 \mathrm{mg} \mathrm{mL}^{-1}$ e controle negativo (CN). Nível de significância $p \geq 0,05\left(^{*}\right)$.

Rev. Bras. PI. Med., Botucatu, v.14, n.4, p.635-642, 2012. 
flavonóides na constituição, como Pterocaulon polystachyum e Achyrocline satureidoides têm sido estudadas através do sistema teste de Allium cepa, e os resultados indicam a presença de atividade antiproliferativa nestes extratos (Knoll et al., 2006; Fachinetto et al., 2007). P. major também possuem flavonóides tóxicos contendo grupos isoprenóides os quais têm demonstrado possuir atividade citotóxica (Shi et al., 2001), o que pode justificar a diminuição dos IM de células de $A$. cepa expostas ao extrato medicinal. Nossos dados corroboram os resultados encontrados para diversas espécies de Plantago, que exibiram atividade anti-carcinogênica e anti-tumoral (Richardson, 2001; Gálvez et al., 2003), com a inibição da divisão celular. A atividade anti-proliferativa atribuída a espécies de Plantago, estão de acordo com a utilização desta planta medicinal pela população.

Os Índices de Efeito Clastogênico (IEC) do
TC foram 0,014; 0,011 e 0,007, nas concentrações 0,$5 ; 1,0$ e $2,0 \mathrm{mg} \mathrm{mL}^{-1}$, respectivamente. No TD 20 horas, esses índices foram 0,008; 0,018 e 0,014. Já no TD 72 horas, esses valores foram 0,009; 0,008 e 0 . Em todos os tratamentos, o $\mathrm{CN}$ apresentou IEC de 0,018 . Nenhuma das concentrações apresentou diferença estatística em relação ao $\mathrm{CN}$, refletindo ausência de ação genotóxica do extrato (Figura 3).

Os Índices de Efeito Aneugênico (IEA) do TC foram 0,005; 0,04 e 0, nas concentrações 0,5; 1,0 e $2,0 \mathrm{mg} \mathrm{mL}^{-1}$, respectivamente. No TD 20 horas, esses índices foram 0,$001 ; 0,002$ e 0,001. No TD 72 horas, esses valores foram 0,002; 0,001 e 0 . Em todos os tratamentos, o CN apresentou IEA de 0,005 . O IEA apresentou diminuição significativa de alterações aneugênicas e os valores médios deste índice demonstram que, além de não determinar aumento de alterações cromossômicas, o que indica ausência

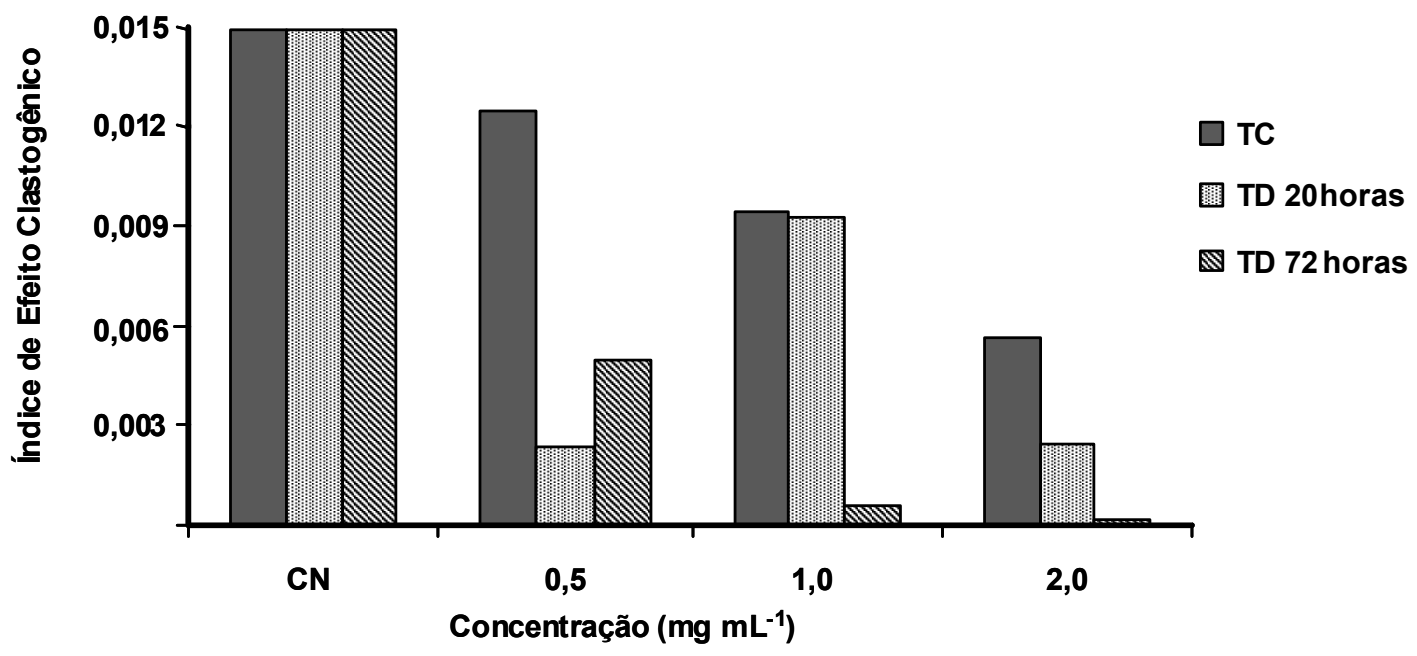

FIGURA 3. Índice de efeito clastogênico em células meristemáticas de Allium cepa expostas aos tratamentos contínuo, descontínuo por 20 e 72 horas, com o extrato hidroalcoólico bruto de folhas de Plantago major, nas concentrações de 0,$5 ; 1,0$ e 2,0 $\mathrm{mg} \mathrm{mL}^{-1}$ e controle negativo (CN).

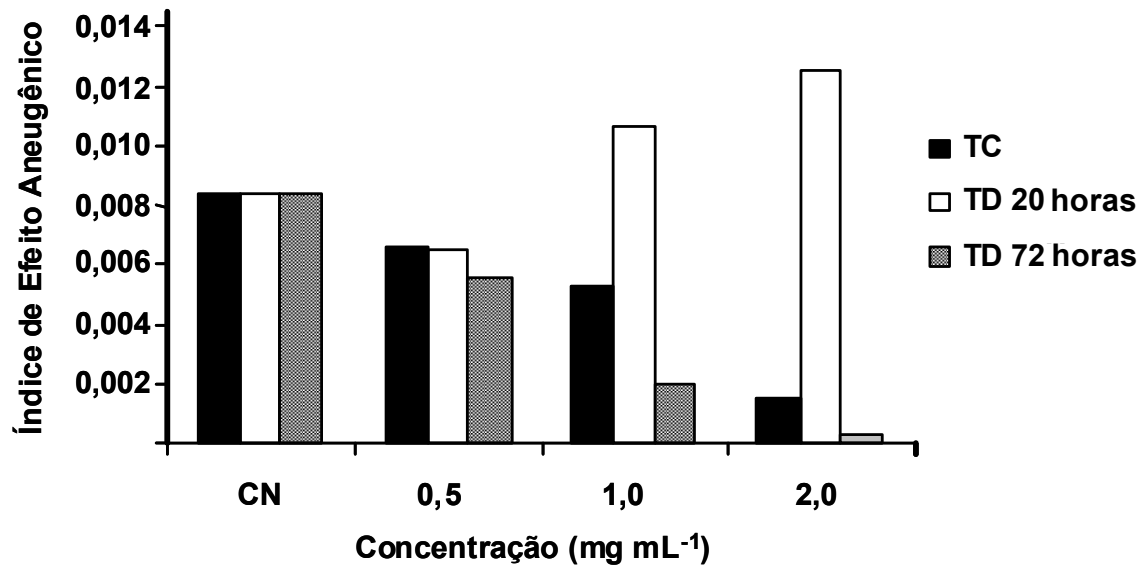

FIGURA 4. Índice de efeito aneugênico em células meristemáticas de Allium cepa expostas aos tratamentos contínuo, descontínuo por 20 e 72 horas, com o extrato hidroalcoólico bruto de folhas de Plantago major, nas concentrações de 0,$5 ; 1,0$ e $2,0 \mathrm{mg} \mathrm{mL}^{-1}$ e controle negativo $(\mathrm{CN})$. 
de ação genotóxica do extrato, sugere ainda que, o EBHPM possui atividade anti-genotóxica (Figura 4). Os resultados encontrados por Askin-Çelik \& Aslanturk (2006) indicam que o extrato aquoso de folhas de $P$. lanceolata também possui efeito antigenotóxico.

Além da avaliação em Allium cepa, os animais foram submetidos ao teste do micronúcleo, este ensaio também visa a determinação da genotoxicidade e mutagenicidade do extrato, além de verificar o efeito citotóxico do mesmo. Para o controle negativo ( $\mathrm{CN})$, a porcentagem de eritrócitos policromáticos micronucleados (EPCMN) foi de $0,017 \%$, enquanto que nos animais tratados com 100 mg do extrato de Plantago major, esse índice atingiu $0,024 \%$. Já os animais que receberam 200 mg tiveram $0,008 \%$ dos EPC portando micronúcleos.

No controle positivo $0,489 \%$ dos EPC eram micronucleados (Figura 5). Não foram encontradas diferenças significativas entre as concentrações testadas do EBHPM (100 e $200 \mathrm{mg}$ por animal) e o $\mathrm{CN}$, apenas o CP apresentou significativo aumento no número de EPCMN.

O micronúcleo em eritrócitos jovens surge principalmente por fragmentos cromossômicos que não são incorporados pelo núcleo das células-filhas durante a divisão celular, e a incidência de PCEMNs pode refletir em danos cromossômicos (Salamone \& Heddle, 1983). Portanto, para as concentrações testadas, o EBHPM não apresentou atividade mutagênica em roedores, corroborando com a indicação do teste biológico vegetal, no qual o extrato de $P$. major não possui atividade mutagênica. Testes in vivo com roedores apresentam resultados ainda mais similares aos efeitos no corpo humano quando comparados aos testes em organismos vegetais, uma vez que são realizados em mamíferos, além dos resultados in vivo sofrerem influência da ação sistêmica.

$\mathrm{Na}$ relação expressa entre o número de eritrócitos policromados (EPC) e o total de células, $(E P C /(E P C+E N C))$, apenas a dose de $100 \mathrm{mg}$ apresentou diferença estatística em relação ao $\mathrm{CN}$, sem portanto diferir estatisticamente do CP (Figura 6).

Lezama et al. (2006) demonstram que tansagem teve efeito hematopoiético em cultura de células de medula óssea e baço de ratos. Já em células de linhagens cancerígenas, o extrato produziu atividade citotóxica. Gálvez et al. (2003) também mostraram inibição do crescimento de células cancerígenas expostas ao extrato de Plantago major. Esses ensaios foram realizados in vitro, porém comparando-os com os resultados aqui obtidos podese inferir que o $P$. major possui mecanismo de ação preventivo. No presente estudo não foi observada atividade mutagênica em camundongos nas concentrações testadas e Lezama et al. (2006) descreveram a atividade antimutagênica do extrato, ou seja, o extrato provocou mutação benéfica.

Os resultados mostram que o extrato de Plantago major não apresenta efeito genotóxico, aneugênico ou clastogênico, quando testado em sistema teste Allium cepa e de medula óssea de roedores, porém indicam atividade citotóxica do mesmo, como observado nos resultados obtidos a partir do Índice de germinação e Índice mitótico em Allium cepa, assim como os resultados da relação entre eritrócitos policromáticos e os normocromáticos em medula óssea de roedores.

A diminuição do índice mitótico em $A$. cepa indica a capacidade deste extrato em diminuir a proliferação celular, sendo um potencial anti-

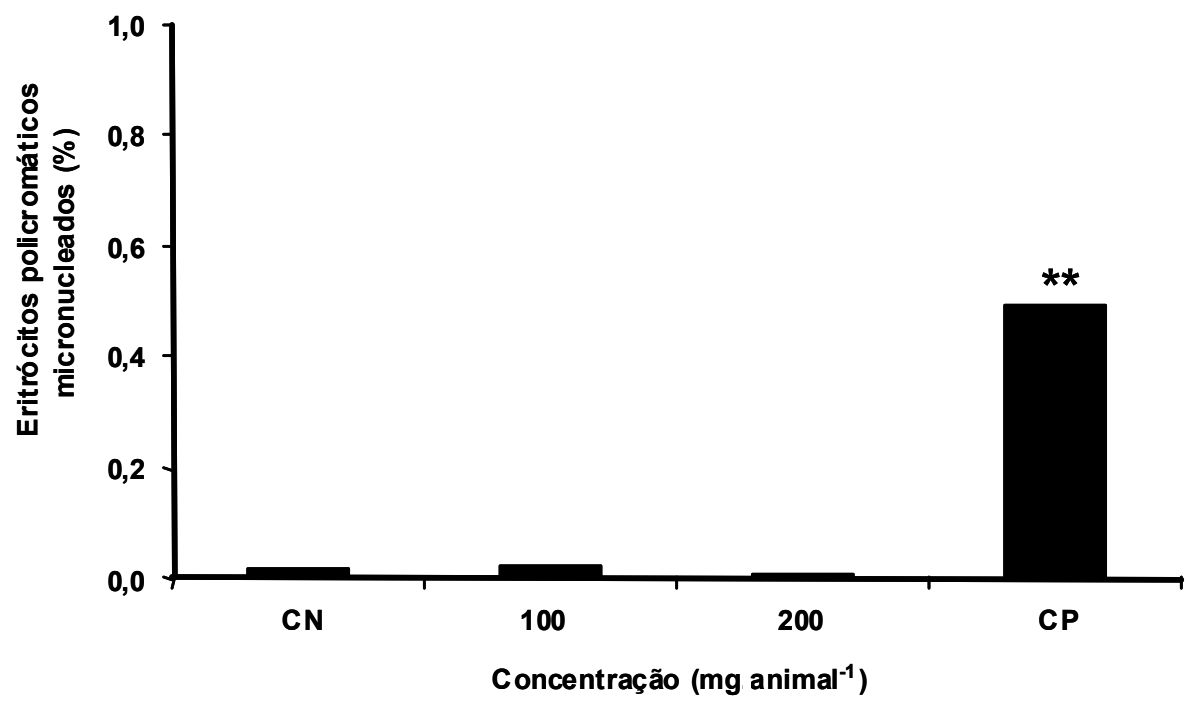

FIGURA 5. Porcentagem de eritrócitos policromáticos micronucleados (PCEMN). Nível de significância p $\left.\geq 0,01{ }^{(* *}\right)$. 


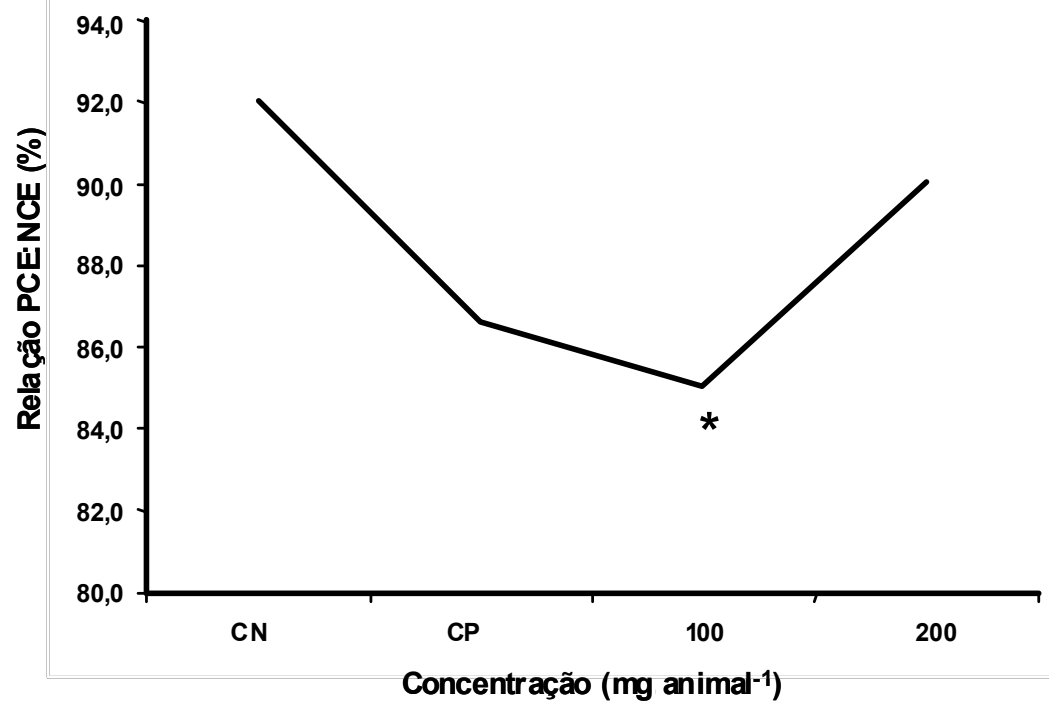

FIGURA 6. Relação entre eritrócitos policromáticos (PCE) e a soma do número PCEs e eritrócitos normocromáticos. Nível de significância $p \geq 0,05\left(^{*}\right)$ e $\left.p \geq 0,01{ }^{(*}\right)$.

carcinogênico e antitumoral, como já relatado para diversas espécies do gênero Plantago. Devido aos conhecidos efeitos mutagênicos e antiproliferativos dos flavonóides (Santos \& Salantino, 2000; Labieniec et al., 2003), abundantes em P. major, e também aos resultados obtidos no presente estudo, torna-se importante a condução de novas pesquisas, como a análise de antimutagenicidade para maior entendimento dos efeitos biológicos do EBHPM no organismo humano.

\section{REFERÊNCIA}

ASKIN-ÇELIK, T.; ASLANTURK, O.S. Anti-mitotic and antigenotoxic effects of Plantago lanceolata aqueous extract on Allium cepa root tip meristem cells. Cellular and Molecular Biology, v.61, n.6, p.693-7, 2006.

BORGES-ARGÁEZ, R. et al. Cytotoxic and antiprotozoal activity of flavonoids from Lonchocarpus spp. Phytomedicine, v.14, p.530-3, 2007.

CARVALHO, R.O. et al. Diesel emissions significantly influence composition and mutagenicity of the ambient particles: a case study in São Paulo, Brazil. Environmental Research, v.98, p.1-7, 2005.

CHACON, D.R. et al. Absence of genotoxic and antigenotoxic effects of a standardized extract of the medicinal plant Solanum melongena on peripheral blood and bone marrow cells of Wistar rats. Cytology, v.67, p.417-22, 2002.

DELMULLE, L. et al. Anti-proliferative properties of prenylated flavonoids from hops (Humulus lupulus L.) in human prostate cancer cell lines. Phytomedicine, v.13, p.732-4, 2006.

FACHINETTO, J.M. et al. Atividade antiproliferativa e mutagênica dos extratos aquosos de Baccharis trimera (Less.) A. P. de Candolle e Baccharis articulata (Lam.) Pers. (Asteraceae) sobre o sistema teste de Allium cepa.
Revista Brasileira de Plantas Medicinais, v.11, n.4, p.360-7, 2009.

FACHINETTO, J.M. et al. Anti-proliferative effect of infusions of Achyrocline satureidoides on the Allium cepa cell cycle. Brazilian Journal of Pharmacognosy, v.17, p.49-54, 2007.

FISKESJÖ, G. The Allium test: a standard in environmental monitoring. Hereditas, v.102, p.99-112, 1985.

GÁLVEZ, M. et al. Cytotoxic effect of Plantago spp on cancer cell lines. Journal of Ethnopharmacology, v.98, n.2, p.12530, 2003.

KNOLL, M.F. et al. Effects of Pterocaulon polystachyum DC. (Asteraceae) on onion (Allium cepa) root-tip cells. Genetics and Molecular Biology, v.29, p.539-42, 2006. $\mathrm{KO}$, R.J. Causes, epidemiology, and clinical evaluation of suspected herbal poisoning. Clinic Toxicology, v.37, n.6, p.697-708, 1999.

LABIENIEC, M. et al. Antioxidant and pro-oxidant effects of tannins in digestive cells of the freshwater mussel Unio tumidus. Mutation Research, v.539, n.1-2, p.19-28, 2003.

LEZAMA, R.V. et al. Effect of Plantago major on cell proliferation in vitro. Journal of Ethnopharmacology, v.103, n.1, p.36-42, 2006.

LORENZI, H.; MATOS, F.J.A. Plantas medicinais no Brasil: nativas e exóticas. Nova Odessa: Instituto Plantarum, 2002. 512p.

MACEDO, M.F.S. et al. Determining the genotoxicity of an aqueous infusion of Bauhinia monandra leaves. Revista Brasileira de Farmacognosia, v.18, p.509-16, 2008. MACGREGOR, J.T. Guidelines for the conduct of micronucleus assays in mammalian bone marrow erythrocytes. Mutation Research, v.189, p103-12, 1987. MORITA, T. et al. Evaluation of the rodent micronucleus assay in the screening of IARC carcinogens. Mutation Research, v.389, p.3-122, 1997.

NOLDIN, V.F. et al. Composição química e atividade biológica de Cynara scolymus L. cultivada no Brasil. 
Química Nova, v.26, n.3, p.331-4, 2003.

RIBEIRO, L.R. et al. Mutagênese ambiental. Rio Grande do Sul: Ulbra, 2003. 355p.

RICHARDSON, M.A. Biopharmacologic and herbal therapies for cancer: research update from NCCAM. Journal Nutrition, v.131, p.3037-40, 2001.

ROBBERS, J.E. et al. Pharmacognosy and pharmacobiotechnology. Baltimore: Willians \& Wilkins, 1996. 898p.

RODRIGUES, L.R.A. et al. Alelopatia em plantas forrageiras. Jaboticabal: FCAVJ-NESP/FUNEP, 1992.18p. SALAMONE, M.F.; HEDDLE, J.A. The bone marrow micronucleus assay: rationale for a revised protocol. In: SERRES, F.J. Chemical mutagen: principles and methods for their detection. Amsterdam: Plenum Press, 1983, p.11-149.

SAMUELSEN, A.B. Traditional uses, chemical constituents and biological activities of Plantago major L. Journal of Ethnofarmacology, v.7, p.1-21, 2000.

SANTOS, D.Y.A.C.; SALANTINO, M.L.F. Foliar flavonoids of Annonaceae from Brazil: taxonomic significance.
Phytochemistry, v.55, n.6, p.567-73, 2000.

SHI, Y.Q. et al. Cytotoxic flavonoids with isoprenoids groups from Morus mongolica. Journal of Natural Products, v.64, p.181-8, 2001.

TAGLIATI, C.A. et al. Acute and chronic toxicological studies of the Brazilian phytopharmaceutical product lerobina ${ }^{\circledR}$. Revista Brasileira de Farmacognosia, v.18, p.676-82, 2008.

TEIXEIRA, R.O. et al. Assessment of two medicinal plants, Psidium guajava L. and Achillea millefolium L. in in vivo assays. Genetics and Molecular Biology, v.26, p.551-5, 2003.

TYLER, V.E. Natural products and medicine: an overview. In: BALICK, M.J. et al. Medicinal resources of the tropical forest, biodiversity and its importance to human health. New York: Columbia University Press, 1996. p.3-10.

VICENTINI, V.E.P. et al. Averrhoa carambola L., Syzygium cumini (L.) Skeels and Cissus sicyoides L.: medicinal herbal tea effects on vegetal and test systems. Acta Scientiarum, v.23, p.593-8, 2001. 